\title{
A contrarreforma do Sistema Único de Saúde: o caso das organizações sociais
}

\author{
The counter-reform of the Unified Health System: the case of social organizations
}

\section{Joseane Barbosa de LIMA*}

Resumo: Esse artigo tem como objeto a análise da privatização da saúde pública brasileira por meio das chamadas Organizações Sociais. Para tal, utilizou-se a pesquisa bibliográfica e a documental. Por meio da pesquisa bibliográfica realizou-se uma análise da trajetória da saúde no Brasil, e mediante a pesquisa documental, isto é, leis e documentos brasileiros que traduzem a contrarreforma do Estado, analisou-se a privatização do SUS com a transferência da gestão pública para as Organizações Sociais.

Palavras-chave: Política de Saúde. Organizações Sociais. Privatização do SUS.

Abstract: This article aims to analyze the privatization of Brazilian public health by means of, so-called, Social Organizations. Bibliographical research was used to analysis of the trajectory of health was carried out for Brazil. Documentary research, of Brazilian laws and documents that translate the counter-reform of the State, was used to analyse the privatization of the SUS by the transfer of management to Social Organizations.

Keywords: Health Policy. Social Organizations. SUS Privatization.

Submetido em: 12/1/2018. Aceito em: 17/2/2018.

\section{Introdução}

$\mathrm{E}$ ste artigo tem por objetivo analisar as tendências de contrarreforma da política de saúde brasileira por meio da transferência da gestão das unidades públicas para as Organizações Sociais da Saúde. Parte-se do pressuposto de que a área da saúde tem se constituído em um mercado lucrativo para o capital e, nesse processo, as empresas privadas de saúde, sob a forma jurídica de Organizações Sociais (OS), têm disputado o fundo público, comprometendo a alocação dos recursos públicos da saúde na sustentação, qualificação e ampliação dos próprios serviços públicos. Para tal, empreende-se a análise sócio-histórica da política de saúde no Brasil, procurando abordá-la em dois grandes momentos: de 1930 a 1960, e a partir dos anos 1960 até a criação do Sistema Único de Saúde (SUS). Posteriormente, analisam-se os marcos regulatórios das OS no Brasil, que apontam para a contrarreforma do SUS.

\section{POLÍTICA DE SAÚdE BRASILEIRA: DA MEDICINA PREVIDENCIÁRIA À CONSTRU- ÇÃO DO SUS}

As primeiras formas de políticas sociais relacionadas à saúde têm sua gênese a partir do século XVIII, como estratégia de legitimação da ordem burguesa e de acumulação do capital.

\footnotetext{
* Assistente Social. Doutora em Serviço Social. Professora Adjunta da Faculdade de Serviço Social da Universidade Federal de Juiz de Fora (UFJF, Juiz de Fora (MG), Brasil). Rua José Lourenço Kelmer, s/n, Martelos, Juiz de Fora (MG), CEP: 36036-330. E-mail: <jo.asocial@hotmail.com>. ORC ID: <https://orcid.org/ooooooo3-2753-4582>.
} 
Apenas a partir da segunda metade do século XX a assistência à saúde da população passa a ser considerada uma questão política governamental, fruto tanto da ampliação das necessidades sociais quanto do acirramento da luta de classes. Nesse contexto, a política de saúde assumida pelo Estado nos países de capitalismo central nasce vinculada ao surgimento da medicina social na Alemanha, França e Inglaterra (BRAVO, 2013).

De acordo com Bravo (2006), no Brasil o Estado só assumirá a política de saúde a partir de 1930, em decorrência das transformações políticas e econômicas vivenciadas pelo país. Anteriormente ao período citado, a assistência médica no país era realizada por meio de ações filantrópicas para aqueles que não podiam pagar e através da prática liberal para a parcela mais abastada. Contudo, é possível identificar no século XIX iniciativas no campo da saúde pública, a exemplo da realização de campanhas limitadas, sendo os últimos anos do século determinantes para a mudança de postura do Estado, devido à emergência das lutas sociais no cenário brasileiro e as reivindicações do nascente movimento operário no país. Desse modo, "[...] a saúde emerge como 'questão social' no Brasil no início do século XX, no bojo da economia capitalista exportadora cafeeira, refletindo o avanço da divisão do trabalho, ou seja, a emergência do trabalho assalariado" (BRAVO, 2006, p. 1-2).

Em 1923, tem início no Brasil a fase previdencialista da saúde, que só seria superada na década de 1980, com a criação do SUS. Datam desse período as primeiras medidas voltadas para a saúde do trabalhador, tendo seu ápice com a criação das Caixas de Aposentadoria e Pensões (CAPs), criadas em 1923, através da Lei Elói Chaves. As CAPs se organizavam por empresas e eram financiadas tanto pelos trabalhadores quanto por empregadores, sendo os benefícios proporcionais às contribuições. Os benefícios previstos eram: assistência médico-curativa, acesso a medicamentos, aposentadoria por tempo de serviço, velhice e invalidez, pensão para os dependentes e auxílio funeral (BRAVO, 2006). Nesse contexto, Bravo (2013) identifica a existência de uma Política Nacional de Saúde organizada em dois subsetores: o de Saúde Pública e o de Medicina Previdenciária.

O subsetor de Saúde Pública era responsável pelo desenvolvimento de ações voltadas à criação de condições sanitárias mínimas para a população urbana e rural. Importante também destacar a criação do Ministério da Educação e Saúde ainda nos anos 1930, compondo-se de dois departamentos: o de Educação e o de Saúde, intitulado Departamento Nacional de Saúde e Assistência Médico-Social (BRAVO, 2006). Já o subsetor de Medicina Previdenciária nasceu com a criação dos Institutos de Aposentadorias e pensões ${ }^{1}$ (IAPs), e teve por objetivo alcançar o maior número de categorias de trabalhadores urbanos possível, como forma de se antecipar às reivindicações em curso na década de 1930. Segundo Bravo (2006), a medicina previdenciária assumirá centralidade em detrimento do setor de saúde pública a partir de 1966, período de unificação dos IAPs por meio do Instituto Nacional de Previdência Social (INPS).

Paim (2009) observa que a promoção da saúde pública não era uma prioridade dos dirigentes do INPS, que optavam pela compra de serviços médico-hospitalares do setor privado, em

\footnotetext{
${ }^{1}$ Nos anos 1930 o Presidente Getúlio Vargas promoveu uma reestruturação do setor previdenciário que resultou na extinção das CAPs e sua substituição pelos IAPs. Por meio destes, a filiação passava a se dar por categorias profissionais, diferente do modelo das CAPs, que se organizavam por empresas.
}

Argum., Vitória, v. 10, n. 1, p. 88-101, jan./abr. 2018. 
detrimento do investimento nos serviços de assistência à saúde do instituto. A década de 1970 será marcada pelo privilegiamento do setor privado de saúde, caracterizado, segundo Correia (2005), por um modelo de assistência à saúde baseado em ações individuais médicohospitalares, sendo hegemônico o modelo médico assistencial privatista.

O alinhamento da saúde aos interesses do capital dá-se no interior do setor previdenciário, expresso na consolidação de um complexo médico-industrial que beneficiou empresas internacionais de produção de medicamentos e de equipamentos médicos, bem como pela compra de serviços médicos privados, que proporcionou o crescimento das empresas médicas. No período em questão, o Estado brasileiro franqueou ao capital privado a prestação de serviços considerados rentáveis, como saúde, educação, habitação e mercado de seguros, em mais de 8o\% (BRAVO, 2006).

O questionamento da saúde como fonte de lucro para o capital foi o eixo que unificou os movimentos sociais no Movimento da Reforma Sanitária ${ }^{2}$ em torno da defesa da saúde pública e contra a sua privatização. Nessa perspectiva, a saúde na década de 1980 deixou de ser interesse apenas dos técnicos, para assumir uma dimensão política, estando estreitamente vinculada à democracia (BRAVO, 2006).

A VIII Conferência Nacional de Saúde (VIII CNS), realizada em março de 1986, configura o marco fundamental para esse debate e defende a exclusividade de alocação de recursos públicos no próprio setor público estatal e em sua rede socioassistencial, em âmbito municipal e estadual, determinando assim "[...] a suspensão imediata de financiamento, por parte destes fundos [...], para ampliação, reforma e construção de estabelecimentos privados ou para compra de equipamentos" (CONSELHO NACIONAL DE SAÚDE, 1986, p. 16). O relatório final da VIII CNS apontou para questões que definiram os rumos constitucionais da política de saúde. Assim, quando a Constituição Federal foi aprovada em 1988, incorporou em grande medida relevantes propostas contidas no referido relatório, trazendo avanços importantes para os direitos sociais no Brasil sob o ponto de vista legal.

A partir da Constituição de 1988, a saúde torna-se um direito social, regulamentado tanto pela Carta Magna quanto pela Lei Orgânica da Saúde (Lei 8.08o/9o). A regulamentação ainda prevê a redefinição da atuação dos entes governamentais (União, Estados e Municípios) na prestação dos serviços. Com o processo de descentralização, a saúde pública foi organizada nos municípios brasileiros, expandindo-se no território nacional.

Entre os principais aspectos aprovados por esta Constituição, têm-se:

- O direito universal à saúde e o dever do Estado, acabando com discriminações existentes entre segurados/não segurados, rural/urbano;

- As ações e serviços de saúde passaram a ser considerados de relevância pública, cabendo ao poder público sua regulamentação, fiscalização e controle;

${ }^{2} \mathrm{O}$ termo Reforma Sanitária diz respeito às diversas experiências de reformulação de leis e normas referentes à assistência à saúde da população, adotadas em diferentes continentes, a exemplo do que ocorreu em países como Itália, Espanha, Portugal e Brasil.

Argum., Vitória, v. 10, n. 1, p. 88-101, jan./abr. 2018. 
- A constituição do Sistema Único de Saúde, integrando todos os serviços públicos numa rede hierarquizada, regionalizada, descentralizada e de atendimento integral, com participação da comunidade;

- A participação do setor privado no sistema de saúde deverá ser complementar, preferencialmente com as entidades filantrópicas, sendo vedada a destinação de recursos públicos para as instituições com fins lucrativos. Os contratos com entidades privadas prestadoras de serviços far-se-ão mediante contrato de direito público, garantido ao Estado o poder de intervir nas entidades que não estiverem seguindo os termos contratuais;

- Proibição da comercialização de sangue e derivados (BRAVO, 2006).

A nova organização da Política de Saúde brasileira por meio da estruturação do SUS e de seus princípios - intersetorialidade, integralidade, descentralização, universalização e participação social - está ancorada na defesa da universalização das políticas sociais, e a garantia dos direitos sociais, na perspectiva da Seguridade Social ${ }^{3}$. Contudo, a consolidação do SUS ocorreu num contexto em que a disputa ideológica favoreceu amplamente o projeto neoliberal, com a introdução de mecanismos da economia de mercado, como a competição gerenciada na organização dos serviços sociais e a redução do papel de provedor do Estado, bem como com a transferência dessa competência a organizações civis lucrativas ou não (FLEURY; LOBATO, 2009). Nesse cenário, a implementação do SUS ocorre por bases distintas daquelas propostas pelos protagonistas do Movimento de Reforma Sanitária.

No próximo item será analisada a contrarreforma do Estado brasileiro por meio das OS, com fortes repercussões na consolidação de uma Política de Saúde pública, universal e de qualidade.

\section{A CONTRARREFORMA DO SUS POR MEIO DAS ORGANIZAÇÕES SOCIAIS DA SA- ÚDE}

A contrarreforma da política de saúde brasileira por meio dos chamados novos modelos de gestão se materializaram mediante leis federais, estaduais e municipais que tratam da criação das Organizações Sociais (OSs) e das Organizações da Sociedade Civil de Interesse Público (OSCIPs), regulamentadas respectivamente por meio das leis no 9.637, de 15 de maio de 1998, e no 9.790, de 23 de março de 1999 (BRAVO; ANDREAZZI, 2014).

As Organizações Sociais são o eixo central do Plano Diretor da Reforma do Aparelho do Estado (PDRE). Argumenta-se que o objetivo é incentivar a produção não lucrativa de bens serviços públicos não exclusivos do Estado, por meio da transferência desses serviços para o terceiro setor, visando ao aprimoramento da gestão pública estatal e não estatal, com base no estabelecimento de alianças estratégicas entre Estado e sociedade, quer para atenuar disfunções operacionais daquele, quer para maximizar os resultados da ação social em geral (BRASIL, 1997).

Nesse contexto de redefinição das funções precípuas do Estado, o Plano Diretor da Reforma do Aparelho do Estado parte da existência de quatro setores dentro do Estado:

\footnotetext{
3 Está inserida na Constituição Federal de 1988, no capítulo da Ordem Social, e é composta pelo tripé Saúde, Previdência Social e Assistência Social.
}

Argum., Vitória, v. 10, n. 1, p. 88-101, jan./abr. 2018. 
- NÚCLEO ESTRATÉGICO - corresponde aos Poderes Legislativo e Judiciário, ao Ministério Público e ao Poder Executivo. Trata-se do governo, em sentido amplo. É no núcleo estratégico que as leis e as políticas públicas são definidas e seu cumprimento é cobrado. É, portanto, o setor onde as decisões estratégicas são tomadas.

- ATIVIDADES EXCLUSIVAS - setor no qual são prestados serviços que só o Estado pode realizar, ou seja, aqueles em que se exerce o poder de regulamentar, fiscalizar, fomentar.

- SERVIÇOS NÃO EXCLUSIVOS - correspondem ao setor onde o Estado atua simultaneamente com outras organizações públicas não estatais e privadas. As instituições desse setor não possuem o poder de Estado, mas este se faz presente porque os serviços envolvem direitos humanos fundamentais, como os da educação e da saúde, ou porque possuem economias externas relevantes, na medida em que produzem ganhos que não podem ser apropriados por esses serviços pela via do mercado. São exemplos desse setor as universidades, os hospitais, os centros de pesquisa e os museus.

- PRODUÇÃO DE BENS E SERVIÇOS PARA O MERCADO - corresponde à área de atuação das empresas estatais do segmento produtivo ou do mercado financeiro. É caracterizado pelas atividades econômicas voltadas para o lucro que ainda permanecem no aparelho do Estado, como, por exemplo, as do setor de infraestrutura (BRASIL, 1997, p. 10).

Todo empenho dá-se no sentido de publicizar os serviços considerados pelo PDRE como não exclusivos do Estado, sob o argumento de aumento da eficiência e qualidade dos serviços, com redução de custos. Os serviços considerados não exclusivos são aqueles em que o Estado atua simultaneamente com outras organizações privadas, tais como educação, saúde, cultura e proteção ambiental, entre outros. A estratégia é transferir os referidos serviços para o chamado setor público não estatal, que, uma vez fomentados pelo Estado, assumirão a forma de Organizações Sociais4.

O Contrato de Gestão é o instrumento-chave na relação entre o Estado e a entidade qualificada como OS. Segundo o MARE (BRASIL, 1997), o contrato configura “[...] um instrumento de implementação, supervisão e avaliação de políticas públicas, de forma descentralizada, racionalizada e autonomizada, na medida em que vincula recursos ao atingimento de finalidades públicas" (BRASIL, 1997, p. 36).

A partir da institucionalização da Lei 9.637/98, os Estados da federação passaram a adotar o modelo de OS na gestão do SUS, destacadamente o Estado de São Paulo. Essa referência ao Estado paulista faz-se necessária por ele ser apresentado como modelo de sucesso na gestão da saúde para outros Estados da federação ${ }^{5}$.

\footnotetext{
4 Trata-se de uma forma de propriedade composta por associações civis sem fins lucrativos, aptas a serem parceiras do Estado na gestão pública, cujas atividades estão voltadas para o atendimento do interesse público.

${ }^{5}$ No Estado do Rio de Janeiro, por exemplo, as OSs na área da saúde foram implementadas sem nenhum estudo prévio de sua viabilidade, pautando-se apenas pela suposta gestão de sucesso e eficiência dos hospitais paulistas geridos por OS, como apontando no Relatório do Tribunal de Contas do Estado do Rio de Janeiro, publicado em 2016.
}

Argum., Vitória, v. 10, n. 1, p. 88-101, jan./abr. 2018. 
A implantação das OSs no Estado de São Paulo ocorreu por meio da Lei Complementar no 846, de 4 de junho de 1998, que autoriza o Poder Executivo a qualificar como Organizações Sociais de Saúde (OSs) entidades sem fins lucrativos, com experiência comprovada no gerenciamento do setor saúde. A referida lei estadual é baseada na lei federal, diferenciando-se quanto à definição de disponibilizar para a administração na modalidade OS somente novos serviços de saúde, com destinação total ou parcial de bens públicos.

Segundo Pereira (2012), nos anos 2008 e 2009, os hospitais geridos pelas OSs custaram aos cofres do Estado de São Paulo, em média, cerca de 50\% a mais do que os hospitais administrados diretamente pelo poder público. Ao cruzar os dados dos relatórios das OSs com informações do Sistema de Gerenciamento da Execução Orçamentária do Estado de São Paulo (SIGEO), a autora supracitada observou que se a contagem for realizada de 2006 a 2009, os gastos com as OSs saltariam de R\$ 910 milhões para R\$ 1,96 bilhão. No mesmo período em que o orçamento do Estado de São Paulo cresceu 47\%, as despesas com a terceirização da saúde cresceram 114\%, mais que o dobro do aumento do orçamento público. Os dados apontados por Pereira (2012) ainda revelam que em 2010, o Hospital Estadual de Guarulhos e o de Francisco Morato, administrados pela Santa Casa de Misericórdia de São Paulo, receberam a mais $\mathrm{R} \$$ 5.474.3815,50 e R\$ 1.040.706,o0, respectivamente (PEREIRA, 2012).

Na capital paulista, as OSs foram regulamentadas por meio da Lei 14.132, de janeiro de 2006, sendo o primeiro contrato assinado em 2007. A pesquisa de Contreiras e Matta (2015) identificou que grande parte dos ajustes regulando a privatização da gestão não eram contratos de gestão, mas convênios. Contudo, essa modalidade - convênio - corresponde à definição jurídica, sua tradicional utilização na administração pública, a saber: um instrumento de fomento a uma entidade privada que realiza atividade de interesse público com sua própria estrutura e pessoal. "Esses convênios reconfigurados se igualam aos contratos de gestão das OSs em seu aspecto fundamental e inovador, a delegação da gestão de equipamento público ao setor privado" (CONTREIRAS; MATTA, 2015, p. 289).

A modalidade convênio foi a estratégia que a prefeitura de São Paulo utilizou para efetivar a privatização da saúde antes da aprovação da lei municipal. Paim (2009), ao analisar as OSs do Estado de São Paulo, identificou que o convênio foi utilizado ainda com entidades que não puderam ser qualificadas como OS por falta de algum requisito legal, o que poderia exigir processos morosos de mudanças no estatuto.

No que concerne à lei municipal das OSs (14.132/2006), pode-se afirmar que ela seguiu a legislação estadual. No entanto, mostrou-se à frente do Estado de São Paulo, porquanto não cerceou a parceria com as OSs aos novos serviços de saúde, podendo estas firmar contrato de gestão para equipamentos já em funcionamento. Os resultados desta parceria ainda não foram objeto de muitos estudos.

Bravo e Andreazzi (2014) esclarecem que a Lei de Responsabilidade Fiscal (LRF) configurou um dos mecanismos básicos para que Estados e municípios aderissem à terceirização por meio das OSs. A LRF6 foi promulgada por meio da Lei no. 101/2000 e estabelece normas e

\footnotetext{
${ }^{6}$ A LRF ficou também conhecida como Lei da Transparência por obrigar os administradores a divulgarem relatórios e demonstrativos dos gastos.
}

Argum., Vitória, v. 10, n. 1, p. 88-101, jan./abr. 2018. 
parâmetros a serem seguidos, relativos ao gasto público de cada ente federativo (Estados e municípios) brasileiro. A imposição de limites nos gastos orçamentários tem por objetivo preservar a situação fiscal dos entes federativos de acordo com seus balanços anuais, visando garantir a saúde financeira de Estados e municípios, a aplicação de recursos nas esferas adequadas e uma boa herança administrativa para os futuros gestores (BRASIL, 2000).

A principal inovação imposta pela referida lei é a fixação de limites para gastos com pessoal. Assim, na esfera federal, o limite máximo para gastos com pessoal passou a ser $50 \%$ da receita corrente líquida. Já para Estados e municípios, o limite é de 6o\%. "Se a despesa total com pessoal ultrapassar 95\% desse limite, a LRF proíbe qualquer movimentação de pessoal que implique aumento de despesa" (BRASIL, 2013, não paginado).

Desse modo, com a LRF foram criadas condicionalidades financeiras relativas aos gastos com saúde, impulsionando a terceirização da gestão e dos serviços nesse setor, como uma estratégia para não atingir o teto determinado pela lei. Isso ocorre porque a contratação de terceiros não é contabilizada para os limites de gastos com pessoal impostos pela LRF. A contratação de mão de obra passa ser de responsabilidade da OS e não do município e/ou do Estado. Na prática, tem-se a ampliação da flexibilização e precarização do trabalho e dos serviços públicos de saúde (com diminuição de concursos públicos) e incentivos à expansão das OSs para todo o país.

A regulamentação das OSs da Saúde nos municípios brasileiros tem sido apresentada como estratégia de ampliação da cobertura assistencial e modernização da gestão da rede municipal de serviços, mas na prática ela se configura como novos modelos de gestão privatizantes, sem compromisso com os princípios defendidos pelo SUS. Essas parcerias entre o público e o privado acontecem no âmbito do livre jogo do mercado, no qual predomina uma dinâmica perversa que reduz o direito ao acesso universal, visto que os contratos de gestão propostos constituem modalidades de privatização que visam à transformação do direito em mercadoria, pois seu objetivo é impulsionar a mercantilização dos setores rentáveis do serviço público. Por meio da celebração de contrato de gestão, o Estado cede para as OSs recursos orçamentários, equipamentos, prédios, bens e servidores públicos, a fim de que entidades privadas prestem serviços pelo SUS, compondo o quadro da privatização da saúde.

\section{Quadro 1. Comparativo da gestão da saúde estatal e da gestão por meio das OSs}

\begin{tabular}{|l|l|}
\hline Sistema Único de Saúde (SUS) & Organizações Sociais (OSs) \\
\hline $\begin{array}{l}\text { Gestão Única do Sistema de Saúde em cada } \\
\text { esfera de Governo (Gestão do Sistema e da } \\
\text { Rede de Ações e Serviços) }\end{array}$ & Autonomia administrativa e financeira de cada OS \\
\hline $\begin{array}{l}\text { Descentralização da gestão entre as três esferas } \\
\text { de Governo }\end{array}$ & $\begin{array}{l}\text { Descentralização das ações e serviços de saúde para a } \\
\text { iniciativa privada e não para os municípios }\end{array}$ \\
\hline $\begin{array}{l}\text { Hierarquização dos serviços, conforme a a } \\
\text { complexidade da atenção à saúde }\end{array}$ & Autonomia gerencial dos serviços de cada OS \\
\hline $\begin{array}{l}\text { Financiamento solidário entre as três esferas de } \\
\text { Governo, conforme o tamanho da população, } \\
\text { suas necessidades epidemiológicas e a a a conforme a influência política de seus dirigentes, com } \\
\text { organização das ações e serviços }\end{array}$ & $\begin{array}{l}\text { Financiamento definido no orçamento público, para cada } \\
\text { "contrapartida da entidade" por meio da venda de } \\
\text { serviços e doações da comunidade, e com reserva de vagas } \\
\text { para o setor privado, lucrativo }\end{array}$ \\
\hline
\end{tabular}

Argum., Vitória, v. 10, n. 1, p. 88-101, jan./abr. 2018. 


\begin{tabular}{|c|c|}
\hline Regionalização & $\begin{array}{l}\text { Inexistente, porque a entidade possui autonomia para } \\
\text { aceitar ou não a oferta regional de serviços, já que seu } \\
\text { orçamento é estabelecido por uma das esferas de Governo }\end{array}$ \\
\hline $\begin{array}{l}\text { Universalidade e integralidade da Atenção à } \\
\text { Saúde }\end{array}$ & $\begin{array}{l}\text { Focalização do Estado no atendimento das demandas } \\
\text { sociais básicas }\end{array}$ \\
\hline $\begin{array}{l}\text { Participação da comunidade, com a política de } \\
\text { saúde definida em Conferências de Saúde }\end{array}$ & Inexistente \\
\hline $\begin{array}{l}\text { Controle Social, com Conselhos de Saúde que } \\
\text { acompanham e fiscalizam a implementação da } \\
\text { política de saúde e a utilização de seus recursos }\end{array}$ & $\begin{array}{l}\text { Inexistente. O controle social, tal como previsto na Lei } \\
8.142 / 90 \text {, é substituído pelos tradicionais conselhos de } \\
\text { administração internos }\end{array}$ \\
\hline
\end{tabular}

Fonte: Rezende (2007).

Informações colhidas na mídia impressa e eletrônica mostram que o processo de contratualização de OSs na área da saúde tem se acelerado nos últimos anos. Ao longo de 17 anos da implantação da Lei no. 9.637/1998, foram adotadas legislações específicas em praticamente todos os Estados, no Distrito Federal e em boa parte dos grandes municípios brasileiros. Segundo a reportagem publicada pelo site Terra (DINO, 2016), nos últimos anos, mais de 200 municípios administrados por diferentes partidos, firmaram contratos com OSs para a gestão de hospitais, ambulatórios, clínicas de especialidades, centros de distribuição de medicamentos e atendimento móvel de urgência, entre outros.

A Pesquisa de Informações Básicas Estaduais (ESTADIC), realizada pelo Instituto Brasileiro de Geografia e Estatísticas (IBGE), demonstrou que 17 Estados da federação no ano de 2013 realizaram contratação de serviços de saúde por meio de OSs. São eles: Amazonas, Roraima, Pará, Maranhão, Piauí, Ceará, Rio Grande do Norte, Paraíba, Pernambuco, Bahia, Espírito Santo, Rio de Janeiro, São Paulo, Santa Catarina, Mato Grosso, Goiás e Distrito Federal (INSTITUTO BRASILEIRO DE GEOGRAFIA E ESTATÍSTICAS, 2014).

Ressalta-se que não foi possível comparar os dados da pesquisa do IBGE (2014), nem colher novas informações sobre as OSs da saúde no país com as informações registradas no Cadastro Nacional de Estabelecimentos de Saúde (CNES), plataforma base para operacionalizar os Sistemas de Informações em Saúde e vinculada à base de dados do Ministério da Saúde, pois ao consultar a referida fonte, constatou-se que o site foi reformulado e que embora as OSs tenham sido inseridas como de natureza jurídica, as informações não estavam disponíveis para consulta 7 .

Em 2014, a pesquisa realizada por Santos (2014) na base de dados no CNES revelou que dos 26 Estados brasileiros mais o Distrito Federal, as OSs estão presentes em 24, totalizando $97 \%$, gerenciando 228 unidades de saúde - de nível estadual ou municipal, como se pode observar na tabela abaixo.

Tabela 1 . Unidades de saúde gerenciadas por Organizações Sociais

\begin{tabular}{l|c} 
Estados & Número de unidades geridas por OSs \\
\hline Acre & 0 \\
\hline Alagoas & 1 \\
\hline Amapá & 3 \\
\hline Amazonas & 0 \\
\hline
\end{tabular}

\footnotetext{
${ }^{7}$ As tentativas de consulta foram feitas no período de dezembro/2016 a fevereiro/2017.
}

Argum., Vitória, v. 10, n. 1, p. 88-101, jan./abr. 2018. 


\begin{tabular}{l|c}
\hline Bahia & 24 \\
\hline Ceará & 10 \\
\hline Distrito Federal & 1 \\
\hline Espírito Santo & 1 \\
\hline Goiás & 5 \\
\hline Maranhão & 0 \\
\hline Mato Grosso & 6 \\
\hline Mato Grosso do Sul & 7 \\
\hline Minas Gerais & 51 \\
\hline Pará & 10 \\
\hline Paraíba & 3 \\
\hline Paraná & 15 \\
\hline Pernambuco & 3 \\
\hline Piauí & 2 \\
\hline Rio de Janeiro & 11 \\
\hline Rio Grande do Norte & 2 \\
\hline Rio Grande do Sul & 6 \\
\hline Rondônia & 1 \\
\hline Roraima & 1 \\
\hline Santa Catarina & 16 \\
\hline São Paulo & 44 \\
\hline Sergipe & 4 \\
\hline Tocantins & 1 \\
\hline Total: 228 & \\
\hline Fonte/Elaboração: Santos (2014, p. 114). &
\end{tabular}

Apesar de o CNES ser uma fonte oficial, é possível observar que os dados não estão em conformidade com a realidade e apresentam um número muito menor de unidades de saúde gerenciadas por OS em alguns Estados. O Estado do Rio de Janeiro, por exemplo, no ano de 2014 já possuía mais de 40 unidades sob a gestão das OSs, conforme os dados da própria Secretaria Estadual de Saúde do Rio de Janeiro (SES/RJ) ${ }^{8}$. Ademais, a pesquisa Estadic (2013) revelou que os Estados do Amazonas e Maranhão realizaram contratualização com OSs no ano de 2013; esses mesmos Estados aparecem no site do CNES, segundo a pesquisa de Santos (2014), com zero unidade transferida à gestão das OSs.

Constata-se que as incoerências dos dados acima apresentados refletem as falhas na alimentação das fontes de dados oficiais do governo, bem como a falta de transparência por parte das secretarias de saúde, o que vai de encontro à lei de acesso a informação (no 12.527, de 2011) e à Portaria no 3.462, de 2010, do Ministério da Saúde, as quais preveem o dever dos gestores de manterem seus dados atualizados junto às bases de dados do referido ministério. Não tem havido o cumprimento do que está previsto em lei. Cabe salientar que a lei de acesso à informação estabelece no seu capítulo II, art. $7^{\circ}$, 'como direito de cidadão, obter informação primária, íntegra, autêntica e atualizada'. Já a Portaria no 3.462/2010, em seu art. 2º , define a obrigatoriedade dos gestores 'de alimentação mensal e sistemática dos Bancos de Dados Nacionais dos Sistemas: Cadastro Nacional de Estabelecimentos de Saúde - CNES, Sistema de Informação Ambulatorial - SIA/SUS, Sistema de Internação Hospitalar - SIH/SUS [...]' (BRASIL, 2010 apud SANTOS, 2014, p. 129).

\footnotetext{
8 No Estado do Rio de Janeiro, 47 unidades públicas de saúde foram transferidas para a gestão das Organizações Sociais (no período de 2012 - sua regulamentação - até 2016). Isso significa, em números: 30 UPAS (todas as UPAS), e 15 hospitais estaduais (de um total de 32 hospitais). Consolida assim a privatização por dentro do SUS no referido Estado.
}

Argum., Vitória, v. 10, n. 1, p. 88-101, jan./abr. 2018. 
Em novembro de 2016, na cidade de São Paulo, foi criado o Instituto Brasileiro de Organizações Sociais da Saúde (IBROSS), primeira entidade nacional representativa das OSs. O IBROSS foi criado por representantes de Organizações Sociais da Saúde (OSs) que atuam em diferentes regiões do país. Em sua página eletrônica, o instituto afirma que seu objetivo principal é "[...] colaborar para o aperfeiçoamento e fortalecimento do Sistema Único de Saúde (SUS) e a qualidade do atendimento oferecido à população brasileira" (INSTITUTO BRASILEIRO DE ORGANIZAÇÕES SOCIAIS DA SAÚDE, 2016, não paginado). Com sede em Brasília (DF), o instituto conta até o momento com 19 instituições associadas. Estas, segundo as informações do instituto, atuam em 13 Estados brasileiros e no Distrito Federal.

As organizações Sociais da Saúde associados ao IBROSS são:

> Associação Congregação de Santa Catarina (ACSC);

$>$ Associação Educadora São Carlos (AESC)/Hospital Mãe de Deus;

> Associação Goiana de Integralização e Reabilitação (AGIR);

$>$ Associação Hospitalar Beneficente do Brasil (AHBB) - Gestão em Saúde;

$>$ Centro de Estudos e Pesquisas Dr. João Amorim (Cejam);

$>$ Hospital Santa Marcelina - Entidade Filantrópica;

$>$ Instituto de Medicina Integral Prof. Fernando Figueira (IMIP);

$>$ Instituto de Responsabilidade Social Sírio-Libanês;

> Instituto de Saúde e Gestão Hospitalar (ISGH);

$>$ Instituto do Câncer Infantil e Pediatria Especializada (ICIPE);

$>$ Instituto Pernambucano de Assistência e Saúde (IPAS);

$>$ Instituto Social Hospital Alemão Oswaldo Cruz;

$>$ Instituto Sócrates Guanaes;

$>$ Santa Casa da Bahia;

> Serviço Social da Construção Civil do Estado de São Paulo (Seconci);

> Sociedade Beneficente Israelita Brasileira Albert Einstein;

> Sociedade Pernambucana de Combate ao Câncer;

> Associação Paulista para o Desenvolvimento da Medicina (SPDM);

$>$ Viva Rio (INSTITUTO BRASILEIRO DE ORGANIZAÇÕES SOCIAIS DA SAÚDE, 2016).

Segundo o IBROSS (2016), as OSs associadas, juntas, gerenciam mais de 800 unidades de saúde e contam com mais de 15 mil leitos; em um ano, sua média de internações chega a 700 mil, e a 750 mil cirurgias. Também são responsáveis por mais de 40 milhões de consultas, quase 50 milhões de exames e chegam a registrar aproximadamente 10 milhões de atendimentos de urgência e emergência. A institucionalização de uma organização representativa das OSs no país corrobora a suspeita de que se está diante de um nicho empresarial consolidado por meio da captação de recursos públicos da saúde para o setor privado, e vinculado a blocos de poder, convertendo a saúde em mercadoria.

Ressalta-se que o art. 199, § $1^{\circ}$, da CF, estabelece que as instituições privadas poderão participar apenas de forma complementar do Sistema Único de Saúde e que as relações entre a administração pública e o setor privado devem ocorrer quando e enquanto a capacidade de oferta do Estado estiver esgotada. No entanto, o que vem ocorrendo com as terceirizações por meio das Organizações Sociais é a transferência pelo Estado, de suas unidades hospitala-

Argum., Vitória, v. 10, n. 1, p. 88-101, jan./abr. 2018. 
res, prédios, móveis, equipamentos, recursos públicos e, muitas vezes, até de pessoal, para a iniciativa privada (REZENDE, 2007).

Esses projetos que visam mudanças no modelo de gestão das políticas sociais estão alinhados às recomendações dos agentes financeiros internacionais que, ao enfatizarem a ineficiência do setor público, buscam introduzir meios privatizantes na esfera pública com o objetivo de expandir a acumulação do capital financeiro internacional, em detrimento de políticas sociais universais.

\section{CONSIDERAÇÕES FINAIS}

O modelo de gestão que tornou possível a terceirização dos serviços de saúde por meio das Organizações Sociais nasceu sob a justificativa da necessidade de o Estado superar sua suposta ineficiência na prestação de serviços. Assim, a proposta de um novo modelo de gestão foi elaborada em 1995, pelo Ministério da Administração Federal e da (Contra) Reforma do Estado, prometendo melhores resultados e economia dos recursos, com o objetivo de organizar governos menos dispendiosos e submetidos ao equilíbrio fiscal. Esse processo culminou na redefinição do papel do Estado, o qual passou a ser mais concentrado no fomento e na regulação, retirando sua função de prestador direto dos serviços públicos. A isso se denominou Administração Gerencial.

A Administração Gerencial consagrou a contrarreforma do Estado brasileiro, visto que impulsionou a mercantilização dos setores rentáveis do serviço público de interesse coletivo, onde se encontram os serviços e as unidades de saúde. Nessa direção, a implementação do modelo de gestão das OSs na área da saúde tem viabilizado a apropriação privada do fundo público da saúde.

É importante destacar que as resistências da sociedade civil organizada contra o projeto do capital vêm dificultando o repasse integral da gestão do SUS para setores não estatais. As resistências ao processo de privatização da saúde têm se dado mediante conselhos e conferências a nível municipal, estadual e nacional, que deliberaram contra as formas de terceirização na saúde e em defesa do modelo de gestão já consagrado na legislação do SUS.

De forma mais incisiva, as lutas em defesa do SUS vêm se realizando através dos Fóruns de Saúde estaduais, que já somam 20 em todo o Brasil, Fóruns Municipais, que totalizam 17, e a Frente Nacional Contra a Privatização da Saúde, constituída em 2010. A Frente é composta por diversas entidades, movimentos sociais, fóruns de saúde estaduais e municipais, centrais sindicais, sindicatos, partidos políticos e projetos universitários, e tem protagonizado as lutas por uma saúde universal, de qualidade e estatal, por meio de mobilizações, atos políticos em defesa da saúde, produção de artigos e organizações de coletânea, reuniões, seminários, rodas de conversas, articulação junto aos trabalhadores, manifestos, cartas abertas, entre outros documentos que contribuem para desvendar a privatização em curso e convocar a população para a defesa do SUS e para o combate aos modelos de gestão privatizantes.

Tendo em vista que os rumos da política de saúde brasileira estão na contramão da consolidação do arcabouço legal do SUS, bem como do Projeto de Reforma Sanitária, faz-se necessário fortalecer cada vez mais esses espaços organizativos e de lutas em defesa de uma saúde

Argum., Vitória, v. 10, n. 1, p. 88-101, jan./abr. 2018. 
pública e de qualidade. Tais espaços tornam-se cada vez mais importantes para o debate contemporâneo sobre a conquista, a consolidação e a universalização do direito à saúde. Por meio deles, os trabalhadores e usuários da saúde pública poderão compreender os caminhos da política de saúde brasileira, fortalecendo o pensar e o agir coletivo na defesa de uma política de saúde pública, universal e de qualidade, e ressaltando a necessidade de defesa de um novo projeto societário, no qual a vida humana não seja negociada como mercadoria.

\section{REFERÊNCIAS}

BRASIL. Presidência da República. Lei n ${ }^{\circ}$ 8.o80, de 19 de setembro de 1990. Dispõe sobre as condições para a promoção, proteção e recuperação da saúde, a organização e o funcionamento dos serviços correspondentes e dá outras providências. Brasília (DF), 1990. Disponível em: <http://www.planalto.gov.br/ccivil_03/leis/l8o8o.htm>. Acesso em: 6 maio 2014 .

BRASIL. Presidência da República. Lei no 8.666, de 21 de junho de 1993. Regulamenta o art. 37, inciso XXI, da Constituição Federal, institui normas para licitações e contratos da Administração Pública e dá outras providências. Brasília (DF), 1993. Disponível em: <http://www.planalto.gov.br/ccivil_03/leis/L8666cons.htm>. Acesso em: 21 jun. 2016.

BRASIL. Ministério da Administração Federal e Reforma do Estado. A Reforma administrativa do sistema de saúde, Caderno MARE, v. 13. Brasília (DF), 1997.

BRASIL. Presidência da República. Lei no 9.637, de 15 de maio de 1998. Dispõe sobre a qualificação de entidades como organizações sociais, a criação do Programa Nacional de Publicização, a extinção dos órgãos e entidades que menciona e a absorção de suas atividades por organizações sociais, e dá outras providências. Diário Oficial [da] República Federativa do Brasil, Brasília (DF), 18 maio 1998. Disponível em:

<http://www.planalto.gov.br/ccivil_03/leis/l9637.htm>. Acesso em: 3 jul. 2013.

BRASIL. Presidência da República. Lei complementar no 101/200o. Estabelece normas de finanças públicas voltadas para a responsabilidade na gestão fiscal e dá outras providências. Brasília (DF), 200o. Disponível em:

<http://www.planalto.gov.br/ccivil_03/leis/LCP/Lcp1o1.htm>. Acesso em: 15 dez. 2016.

BRASIL. LRF, Lei de Responsabilidade Fiscal, os limites para o endividamento de União, estados e municípios e as metas fiscais anuais. Revista de audiência pública do senado federal, Brasília (DF), ano 4, n. 16, jul. 2013. Disponível em:

<https://www.senado.gov.br/NOTICIAS/JORNAL/EMDISCUSSAO/upload/201303\%20\%2ojulho/pdf/em\%2odiscuss\%C3\%A3o!_julho_2013_internet.pdf >. Acesso em: 7 nov. 2017.

BRAVO, M. I. Política de saúde no Brasil. Brasília (DF), 20oo. Disponível em: < http://www.fnepas.org.br/pdf/servico_social_saude/texto1-5.pdf>. Acesso em: 15 dez. 2016.

BRAVO, M. I. A política de saúde no Brasil. In: MOTA, A. E. et al. (orgs.). Serviço Social e saúde: formação e trabalho profissional. 4 ed. São Paulo: Cortez, 2006.

Argum., Vitória, v. 10, n. 1, p. 88-101, jan./abr. 2018. 
BRAVO, M. I. Saúde e Serviço Social no capitalismo: Fundamentos sócio-históricos. São Paulo: Cortez, 2013.

BRAVO, M. I; ANDREAZZI, F. Privatização da gestão e organizações sociais na atenção à saúde. Trabalho, Educação e Saúde, Rio de Janeiro, v. 12 n. 3, p. 499-518, set.-dez. 2014.

CONSELHO nacional de saúde. Relatório Final. Brasília (DF), 1986. In: CONFERÊNCIA NACIONAL DE SAÚDE. Relatório... Brasília (DF), 1986. Disponível em:

<http://conselho.saude.gov.br/biblioteca/Relatorios/relatorio_8.pdf>. Acesso em: 8 dez. 2014 .

CONTREIRAS, H.; MATTA, G. Privatização da gestão do sistema municipal de saúde por meio de Organizações Sociais na cidade de São Paulo, Brasil: caracterização e análise da regulação. Caderno Saúde Pública, Rio de Janeiro, fev. 2015.

CORREIA, Ma Valéria. O Conselho Nacional de Saúde e os rumos da política de saúde brasileira: mecanismo de controle social frente às condicionalidades dos organismos financeiros internacionais. 2005. Tese (Doutorado em Serviço Social)-Faculdade de Serviço Social, Universidade Federal de Pernambuco, Recife, 2005.

FLEURY, S.; LOBATO, L. Participação, Democracia e Saúde. Rio de Janeiro: Cebes, 2009.

INSTITUTO brasileiro de geografia e estatística. Pesquisa de Informações Básicas Estaduais: perfil dos estados brasileiros: 2013. Rio de Janeiro, 2014. Disponível em:

<ftp://ftp.ibge.gov.br/Perfil_Estados/2013/estadic2013.pdf>. Acesso em: 23 de out. 2015.

INSTITUTO brasileiro de organizações sociais em saúde. Apresentação. Brasília (DF), 2015. Disponível em: <http://www.ibross.org.br/apresentacao/>. Acesso em: 13 nov. 2016.

PAIM, J. O que é o SUS? (Coleção Temas em Saúde). Rio de Janeiro: Fiocruz; 2009.

PEREIRA, V. L. A privatização da saúde através das Organizações Sociais (OSs). Esquerda Marxista, São Paulo, 25 jun. 2012. Disponível em: <http://www.marxismo.org.br/content/aprivatizacao-da-saude-atraves-das-organizacoes-sociais-oss/>. Acesso em: 02 out. 2016.

DINO. Organizações Sociais da saúde criam entidade nacional representativa. Portal Terra, São Paulo, 25 nov. 2016. Disponível em:

<https://www.terra.com.br/noticias/dino/organizacoes-sociais-de-saude-criam-1-entidadenacionalrepresentativadosetor,489563d9cad2578d6oc8dff721e536910nfzme2n.html>. Acesso em: 15 dez. 2016.

REZENDE, C. A. P. O modelo de gestão do SUS e as ameaças do projeto neoliberal. In: BRAVO, M. I. et al. (Org.). Política de Saúde na atual conjuntura: modelos de gestão e agenda para a saúde. Rio de Janeiro: ADUFRJ, 2007. 
SANTOS, V. As Organizações Sociais e a privatização do SUS no contexto de contrarreformas do estado brasileiro. 2014. Dissertação (Mestrado em Serviço Social) - Programa de Pós-Graduação da Universidade Federal de Alagoas, Sergipe, 2014.

SÃO PAULO (Estado). Organizações Sociais da Saúde qualificadas. São Paulo, 2010. Disponível em:

<http://www.prefeitura.sp.gov.br/cidade/secretarias/gestao/organizacoes_sociais/index.php ? $\mathrm{p}=14921>$. Acesso em: 15 dez. 2014.

\section{Joseane Barbosa de LIMA}

Assistente Social. Mestra e Doutora em Serviço Social. Professora Adjunta da Faculdade de Serviço Social da Universidade Federal de Juiz de Fora (UFJF, Juiz de Fora, Brasil). 